\title{
Is current EU food safety law geared up for fighting food fraud?
}

\author{
Bernd van der Meulen ${ }^{1}$
}

Published online: 3 November 2015

(c) The Author(s) 2015. This article is published with open access at Springerlink.com

\begin{abstract}
Malicious intent appears to be a blind spot in European Union (EU) food safety law. The current system of law has been created in reaction to food safety incidents. As a consequence it has been designed to deal with accidental problems not with intentionally deceitful actions of people. The horsemeat scandal raised awareness to crime in the food chain. Can instruments of EU food safety law-recall in particular-be applied to deal with fraud? Different EU member states have answered this question differently in situations where the fraud has not caused the affected foods to be injurious to health. A closer look at food fraud shows that this concept covers a wide variety of actions. These actions have an intent to mislead in common but may differ in their effects on public health. The article argues that recall should be reserved to situations where food safety really is at stake and that to other situations of fraud financial instruments should be applied.
\end{abstract}

The "Food Science Dialog" took place from September 15th to 18th 2015 in Hamburg, Germany and was hosted and organized by the Hamburg University of Applied Science (HAW), the Authority of Health and Consumer Protection (BGV) and the Authority for Science and Research (BWF) in Cooperation with the University of Wageningen, Netherlands.

Bernd van der Meulen

Bernd.vanderMeulen@wur.nl

1 Wageningen University, Wageningen, The Netherlands

\section{Origins of food safety law}

Food law, like most defence systems is designed considering the most recent struggle. It provides what in hindsight was needed to win this struggle. When EU food safety law was fully reorganised in the first decade of the 21st Century, the most recent struggle was the BSE crisis. This particular origin has had a profound impact on the shape the reorganisation has taken. Nobody wanted BSE to happen and nobody intentionally created the problem. In this respect the recast of EU food safety law started from a very different ground zero than for example the recast of food safety law in China. For China the most recent struggle that prompted reorganisation was the Melamine crisis. Melamine had been added intentionally and maliciously to dairy products in order to hide dilution. From the outset the reform of Chinese food safety law was concerned about crime.

The EU reform started from a different "enemy image". Nowhere this image is more clearly expressed than in Article 3(14) of Regulation (EC) 178/2002 (the General Food Law; GFL). This provision provides a definition of the concept of hazard:

"Hazard means a biological, chemical or physical agent in, or condition of, food or feed with the potential to cause an adverse health effect".

In this "article of faith" the EU legislature shows that it sees micro-organisms, toxins and physical agents (such as sharp objects or radioactivity) as the enemy that EU food safety law sets out to overcome. It seems that the EU legislature perceives food safety accidents as something waiting to happen in a world of responsible food business operators who are in 
principle willing to contribute to the best of their abilities to prevent such accidents. Neatly fitting in this line of thinking, the General Food Law states in recital 17: "Where food law is aimed at the reduction, elimination or avoidance of a risk to health, the three interconnected components of risk analysis-risk assessment, risk management, and risk communication-provide a systematic methodology for the determination of effective, proportionate and targeted measures or other actions to protect health".

Businesses are required to prevent food safety problems through "hygiene" (Regulations (EC) 852-854/2004), to be prepared to deal with food safety issues through 'traceability' (Article 18 GFL) and to respond to safety incidents through 'withdrawal and recall' (Article 19 GFL).

\section{Prior food law}

This emphasis on a science-based assessment of hazards forms a radical departure from older food law. Earlier on food law had to face a wide variety of counterfeiting practices such as adding milk to water, brick to chili powder, sand to coffee, chalk to bread, etc. For a colourful account see Wilson (2008). Already in 1820 Fredrick Accum exposed abysmal practices in London.

The major issue facing food law was falsification. To be able to combat falsified foods, national legislators felt compelled to lay down in legislation the composition and properties of true foods in product standards. Placing foods on the market not conforming to the legal standard was penalised and prosecuted.

Given the fundamentally differing food cultures in Europe, it should come as no surprise that the legal definitions of true foods differed considerably from country to country. When these countries joined in what is now the European Union these differences in legal product standards posed major challenges for the creation of a common market. When attempts to harmonise product standards at EU level failed, the Court in Luxembourg stepped in. In its famous "Cassis de Dijon" case law it articulated the principle of mutual recognition. Except for serious issues such as concerns for public health, national product standards regardless their country of origin hold an equal rank in the entire common market. Products conforming to any national standard in principle have access to the entire EU territory. This placed a challenge on national food inspectors to distinguish within the category of foods not compliant with national product standards "foreign" from "fraud", that is to say "non-compliant but legal" from "non-compliant and therefore illegal". After the articulation of the principle of mutual recognition followed a shift in food legislation from product standards (also known as vertical legislation) to general requirements (also known as horizontal legislation). In the year 1979 a general directive was created requiring food labels to list all ingredients used (Council Directive 79/112/EEC of 18 December 1978 on the approximation of the laws of the Member States relating to the labelling, presentation and advertising of food stuffs ${ }^{1}$ ). The notion of true foods as foods complying with food standards shifted to foods transparent about their composition. The ultimate consequence of this thinking has become apparent in the practice of "tumbling" chicken meat. "Tumbling" is a euphemism for adding water. The British Food Standards Agency was concerned about this practice and monitored it in the early 2000s. I did not systematically go through the reports, but the highest percentage of added water that caught my eye was close to $50 \%$. It goes without saying that consumers will feel cheated. However, as long as the product is placed on the market not as "chicken" but as a "chicken product" and the ingredients are listed truthfully (i.e. chicken and water and probably some protein to bind the water), the situation is fully legal under current EU food law.

This perception changed under the horsemeat scandal. As has extensively been described elsewhere, the substitution of beef by horse meat sparked public outrage and compelled food safety authorities to act.

\section{Galloping food law}

Within the different EU members an interesting diversity emerged regarding to what extent instruments from EU food safety law can be used to deal with food fraud. The most pressing issue was the question whether authorities should and could mandate a recall based on Article 19 GFL (Van der Meulen et al. 2015). Ireland and Italy believe that Article 19 GFL requires a level of unsafety not present in the horsemeat scandal. Lacking any power in national law outside the GFL, they refrained from imposing a recall. Germany and France also believed that the requirements of Article 19 GFL are not met, but in these countries national legislation provides the power to impose a recall in situations of non-

\footnotetext{
${ }^{1}$ Later replaced first by Directive 2000/13, now by Regulation $1169 / 2011$.
} 
compliance not covered by Article $19 \mathrm{GFL}^{2}$ Greece, The Netherlands and Portugal finally consider Article 19 GFL applicable to the horse fraud. The Netherlands in particular imposed a recall regarding 50,000 tons of product. After the initial perpetrators went into bankruptcy this obligation was enforced against their customers.

Article 19 GFL imposes a recall obligation in case a food business operator "has reason to believe" that a food "is not in compliance with food safety requirements". Accordingly, the first issue is whether the horsemeat scandal presented a safety issue. Initially the focus was on horsemeat. A risk was perceived that it might be contaminated with veterinary drugs (Phenylbutazone in particular). The European Food Safety Authority (EFSA) and the European Medicines Agency (EMA) jointly issued a risk assessment (2013) estimating the likelihood of a consumer sustaining damage from this source at about 1:100.000.000. In other words, this particular risk was considered virtually absent. Then the risk perception shifted to the possibility that the horses might not have undergone the required ante mortem inspection and approval for slaughter for human consumption. Finally, the risk perception settled on the disruption of traceability (Article 18 GFL). The fraud included tampering with bookkeeping and thus with traceability. By consequence, there was doubt about the origin of any products and raw materials placed on the market by the fraudsters; not only the horsemeat, but all raw materials including the beef. ${ }^{3}$

This in turn leads to the question if disrupted traceability is a food safety issue. In other words, is there a concept of (un-)safety in EU food law beyond measurable properties of a product; is there such a thing as "administrative" (un-)safety? To say it yet differently, does EU food law apply a substantive concept of unsafe food or (also) a formal concept?

\section{Formal unsafety}

What is it that Article 19 GFL has in mind where it refers to "food safety requirements"? It has been argued that this reference is to all legal requirements that have been put in place with a view to food safety

\footnotetext{
${ }^{2}$ Also under the new Chinese Food Safety Law a recall can be imposed for non-compliances beyond food safety issues.

${ }^{3}$ From this line of thinking, a German court deduced the possibility that of a BSE risk as the cattle might not have undergone BSE testing.
}

(Van der Meulen 2012). In this reasoning for example all foods contaminated to a level above an applicable MRL would come under Article 19 GFL even though due to the wide safety margins included in MRLs they would in most situations not be injurious to health. It would fit neatly in this interpretation to argue that also Article 18 GFL on traceability is a food safety requirement and thus is within the ambit of Article 19 GFL's recall obligation.

Another interpretation (Meyer and Streinz 2007) is that food safety requirements in Article 19 GFL refers exclusively to Article 14 GFL. A strong argument in favour of this interpretation is that Article $14 \mathrm{GFL}$ bears the heading "Food safety requirements". In this reading the question would narrow down to: is a food whose traceability has been compromised unsafe within the meaning of Article 14 GFL? Article 14 brings foods that are injurious to health under the concept unsafe along with foods that are unfit for human consumption. Unfit for human consumption is further defined as "unacceptable for human consumption according to its intended use, for reasons of contamination, whether by extraneous matter or otherwise, or through putrefaction, deterioration or decay" (Article 14(5) GFL). Until the CJEU ruling in the Berger case there was uncertainty whether such deterioration should be seen as a basis for a (refutable) legal assumption of injuriousness or if there exists a separate category of foods that are not injurious to health but nevertheless are unsafe. In Berger the CJEU (2013) has chosen the latter interpretation.

From accepting that a food can be unsafe without being harmful to accepting that a food can be unsafe for administrative reasons does not seem to present a major step even though it clearly goes outside the wording of Article 14 GFL.

Ultimately, only the CJEU can provide the final interpretation of the scope of the recall-obligation of Article 19 GFL. Apart from what is already in the law, however, the question begs itself if and to what extent recall is the right instrument to deal with food fraud. To put this question into perspective, we need to take a closer look at the phenomenon of food fraud.

\section{What is food fraud?}

The Global Food Safety Initiative (GFSI) presented an inventory of several types of behaviour that may come within the ambit of food fraud. These are the following: 
- Counterfeiting

- Dilution

- Substitution

- Concealment

- Mislabelling

- Grey market/theft and

- Unapproved enhancements.

Theft will not be discussed here. The other concepts can be understood as follows.

Counterfeiting generally means presenting a product as something different from what it really is. One could think of a brand, but also of a protected designation or other mark indicating a certain religious (Halal, Kosher), quality (Fairtrade, organic) or safety (BRC, IFS, FSSC 22.000) profile.

Dilution is creating more bulk by adding cheap substances such as water. As indicated above, in the beginning of the 2000s the UK FSA monitored the addition of water to meat in general and to chicken meat in particular. Such practice may be legal if the water is indicated on the label. Dilution mainly is a quality issue but may become a matter of counterfeiting or a safety issue as well as has been set out above in relation to melamine.

Substitution presents a different species than declared. This practice is rather common in fish. Also the horsemeat scandal mainly comes within this category.

Concealment covers measures taken to hide certain undesirable aspects of a product such as poor quality, deterioration or dilution. Colourants or other chemicals may be used for this purpose. Melamine was added to milk for the purpose of concealment.

Mislabelling may apply to all forms of food fraud, but the expression is mainly used to indicate distortion of the information provided on the label such as durability marking.

Unapproved enhancements directly relate to authorisation requirements. An increasing variety of types of ingredients may only be used in case the product at issue is approved. Any synthetic product, for example, used for a technological purpose is a food additive and may only be used if it is included in the positive list added to Regulation (EC) 1333/2008. Something similar applies to vitamins and minerals in food supplements, novel foods and GMOs. Probably the discharge of waste into food (or feed) may come under this heading.

Already this short explanation shows that the label "food fraud" covers a wide variety of actions. The (sub-)headings proposed by GFSI should not be seen as sharply delineated categories but rather as tools to aid in understanding. As these categories overlap, one type of behaviour may come under different headings.

In some situations risks to human health and a need to recall for the protection of consumers are immediately apparent. In other situations this is less evident. What is present in all situations is a measure of deceit and disregard for consumers' interests creating a certain level of uncertainty.

\section{A concept}

Spink and Moyer (2011) propose as definition for food fraud "the deliberate and intentional substitution, addition tampering or misrepresentation of food, food ingredients or food packaging, labelling, product information, or false or misleading statements made about a product for economic gain that could impact consumer health”. In my view the essence of food fraud is that it is intentional and that it creates a falls impression regarding the true properties of the product. While it seems highly likely that such intentional deception will usually be done for economic gain, I do not think it to be beneficial to consider this element part of the definition. If the same is done for some other reason a separate category emerges (such as food defence in case the intention is to cause harm). Also I object to including the element that it could "impact consumer health". Obviously, a possible negative impact on health is of vital importance. However, it confuses relevant parts of the discussion to include it in the definition. Again a separate category would need to be distinguished of misrepresentations that do not impact consumer health and therefor would not qualify as food fraud if this were to be accepted as part of an official definition.

For these reasons I propose to retain only the first part of the definition and to define food fraud as "the deliberate and intentional substitution, addition tampering or misrepresentation of food, food ingredients or food packaging, labelling, product information, or false or misleading statements made about a food product".

\section{Discussion}

Under the heading of food fraud a variety of behaviours are grouped that aim to mislead the consumer. It goes without saying that consumers must be protected against such behaviour. If on top of the deceit, 
there is reason to believe that a product may be injurious to health, consumer protection should take the shape of recall. If this is not the case, however, in my view financial instruments to compensate the consumer and to deter the perpetrator are called for, rather than food safety measures.

\section{Conclusion}

EU food safety law is designed to protect consumers from substances and organisms not to fight food fraud. There exists a measure of uncertainty regarding the extent to which it can nonetheless be applied to deceptive practises. In my view food safety measures should be reserved for situations where consumers' health is under threat. Fraud should be dealt with financially.

Open Access This article is distributed under the terms of the Creative Commons Attribution 4.0 International License (http://creativecommons.org/licenses/by/4.0/), which permits unrestricted use, distribution, and reproduction in any medium, provided you give appropriate credit to the original author(s) and the source, provide a link to the Creative Commons license, and indicate if changes were made.

\section{References}

CJEU (2013) case C-636/11 Karl Berger v. Freistaat Bayern. 11 April 2013

Frederick Accum (1820) A treatise on adulterations of food, and culinary poisons. Exhibiting the fraudulent sophistications of bread, beer, wine, spiritous liquors, tea, coffee, cream, confectionery, vinegar, mustard, pepper, cheese, olive oil, pickles, and other articles employed in domestic economy and methods of detecting them. By Ab'm Small, London. http://www.gutenberg.org/ebooks/19031. Accessed 8 Oct

Joint Statement of EFSA and EMA (2013) On the presence of residues of phenylbutazone in horse meat. EFSA J 11(4):3190

Meyer AH, Streinz R (2007) LFBG - BasisVo. Lebensmittel- und Futtermittelgesetzbuch Verordnung (EG) 178/2002. Kommentar, C.H. Beck, München

Spink J, Moyer DC (2011) Defining the public health threat of food fraud. J Food Sci 76(9):157-168

van der Meulen BMJ (2012) The core of food law. A critical reflection on the single most important provision in all of EU food law. Eur Food Feed Law Rev 3:117-125

van der Meulen S, Boin G, Bousoula I, Conte-Salinas N, Paganizza V, Montanari F, Fuentes VR, van der Meulen BMJ (2015) Fighting food fraud: horsemeat scandal. use of recalls in enforcement throughout the EU. Eur Food Feed Law Rev 1:2-13

Wilson B (2008) Swindled: the dark history of food fraud from poisoned candy to counterfeit coffee. Princeton University Press. The first chapter is available online http://press. princeton.edu/chapters/s8723.pdf. Accessed 8 Oct 